\title{
The emerging role of a newborn screening program for congenital hypothyroidism: a prospective study
}

\author{
Kumar S. ${ }^{1}$, Ahmed M. ${ }^{2 *}$, Upadhyay N. ${ }^{3}$ \\ DOI: https://doi.org/10.17511/ijpr.2020.i02.02
}

${ }^{1}$ Saurabh Kumar, Associate Professor, Department of Pediatrics, Chirayu Medical College and Hospital, Bhopal, Madhya Pradesh, India.

2* Minhajuddin Ahmed, Assistant Professor, Department of Pediatrics, Chirayu Medical College and Hospital, Bhopal, Madhya Pradesh, India.

3 Nitesh Upadhyay, Assistant Professor, Department of Pediatrics, Chirayu Medical College and Hospital, Bhopal, Madhya Pradesh, India.

Aim: The current study aims to evaluate the incidence \& screening of neonates for congenital hypothyroidism for timely diagnosis and integral psychomotor development. Material \& Methods: A prospective study was carried out in the Department of Pediatrics, Chirayu Medical College \& Hospital Bhopal, India from a period from January 2015 to December 2018. All newborns with the gestational age of 34 weeks or more delivered in the hospital during the study period were screened for hypothyroidism and analyzed. Result: A total of 1363 babies were enrolled out of which 1272 were an eligible candidate for the study period. Numbers of term deliveries were 1109 and preterm deliveries were 163, with 665 (52.28\%) males and 607 (47.72\%) female babies. Of the total eligible neonates, 1109 were term babies and 163 were preterm babies with more than 34 weeks. Neonatal thyroid-stimulating hormone was estimated in all 1272 neonates out of which 2 cases were positive for $\mathrm{CH}, 12$ cases had initially high values between 10-19 $\mu \mathrm{IU} / \mathrm{L}$ but later on, repeat testing after two weeks were found to be within normal limits and rest all 1258 cases were normal. Conclusion: Timely diagnosis and treatment of $\mathrm{CH}$ are important in order to prevent its consequences. NBS is the need of the hour for early diagnosis of $\mathrm{CH}$, which is simple, fast as well as cost-effective.

Keywords: Congenital Hypothyroidism, Neonate, Thyroid hormone

Corresponding Author

Minhajuddin Ahmed, Assistant Professor, Department of Pediatrics, Chirayu Medical College and Hospital, Bhopal, Madhya Pradesh, India. Email: minzahmad@yahoo.co.in

\section{How to Cite this Article}

Kumar S, Ahmed M, Upadhyay N. The emerging role of a newborn screening program for congenital hypothyroidism: a prospective study. Pediatric Rev Int J Pediatr Res. 2020;7(2):56-61.

Available From

https://pediatrics.medresearch.in/index.php/ijpr/arti cle/view/568
To Browse

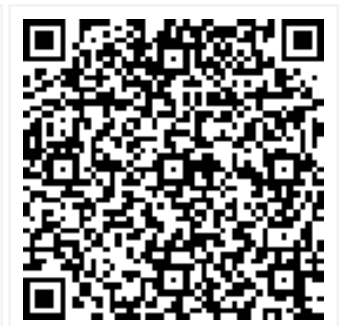

Manuscript Received 2020-01-20

Conflict of Interest No
Review Round 1 2020-01-30

Funding Nil
Review Round 2 2020-02-06

Ethical Approval Yes
Review Round 3

Plagiarism X-checker $8 \%$
Accepted 2020-02-11

Note

(c) 2020 by Saurabh Kumar, Minhajuddin Ahmed, Nitesh Upadhyay and Published by Siddharth Health Research and Social Welfare Society. This is an Open Access article licensed under a Creative Commons Attribution 4.0 International License https://creativecommons.org/licenses/by/4.0/ unported [CC BY 4.0]. 


\section{Introduction}

Congenital hypothyroidism $(\mathrm{CH})$ is defined as thyroid hormone deficiency present at birth. Thyroid hormone plays a vital role in the normal development of the central nervous system. Congenital Hypothyroidism is one of the most common causes of the preventable and treatable cause of mental retardation and intellectual disability. In various neonatal screening programs, it has an incidence of 1: 4000 live births [1]. It was first performed by Dassault in Quebec, Canada in 1972 and they detected 7 cases of $\mathrm{CH}$ among 47000 newborns during 3 years [2]. The thyroid gland develops from a midline thickening of the pharyngeal floor and paired caudal extensions of the fourth pharyngobranchial pouches.

Thyroid hormone is very essential for brain development during 1-2 years of life. The need for neonatal screening for $\mathrm{CH}$ is essential as the majority of sign and symptoms does not exhibit until 3 month of age due to residual thyroid function or transplacental passage of maternal thyroid hormone [3]. If being delayed or neglected, it may cause mental retardation. The clinical manifestations are often subtle or not present at birth.

Common symptoms include decreased activity and increased sleep, feeding difficulty, constipation, and prolonged jaundice while myxedematous facies, large fontanels, macroglossia, a distended abdomen with umbilical hernia and hypotonia are common signs. To assess the various causes of congenital hypothyroidism one should ascertain the site of defect, whether it is in the thyroid gland, thyroid regulatory system, due to deficient thyroid hormone receptor activity or due to inborn errors of the thyroid hormone synthesis.

Most congenital hypothyroidism is caused by defects in the thyroid gland itself (primary hypothyroidism). Causes of primary congenital hypothyroidism can be broadly classified as the failure of the thyroid gland to develop normally (dysgenesis) or failure of a structurally normal thyroid gland to produce normal quantities of thyroid hormone (dyshormonogenesis). Thyroid dysgenesis which encompasses the spectrum of thyroid agenesis, hypoplasia, and ectopy-is the most common cause of congenital hypothyroidism, and its incidence (about 1:4000 infants) has not changed significantly over the last several decades.
The thyroid-stimulating hormone receptor (TSHR) and the transcription factors $P A X 8, N K X 2-1$, and FOXE1 are all expressed in the developing thyroid, and disruption of any of these genes can lead to failure of normal thyroid gland formation [4].

Congenital hypothyroidism may be permanent (thyroid aplasia, hypoplasia, ectopia or dyshormonogenesis) or transient (due to maternal blocking antibodies, iodine excess or deficiency, or some types of dyshormonogenesis [5]. Central hypothyroidism is caused by dysfunction of hypothalamic or pituitary control of the thyroid axis that leads to inadequate production and/or bioactivity of TSH. Congenital hypothyroidism of central origin is rare. Permanent $\mathrm{CH}$ required lifelong treatment and monitoring whereas, transient $\mathrm{CH}$ shows normal thyroid hormone production after the first few months. TSH screening is more sensitive for diagnosis, while T4 is more specific. This study is an attempt to find out the incidence of $\mathrm{CH}$ in our hospital, which is a tertiary level medical college in central India, where we are doing regular neonatal screening for $\mathrm{CH}$.

\section{Materials \& Methods}

Setting: Department of Pediatrics, Chirayu Medical College \& Hospital, Bhopal, Madhya Pradesh, India.

Duration: A period from January 2015 to December 2018.

Type of study: A Prospective Study.

Sampling method: All live newborn gestational age $>34$ weeks delivered in Chirayu Medical College and outborn delivered with an age of fewer than five days.

Sample size: A total of 1363 babies were enrolled, but 1272 were an eligible candidate for the study period

Inclusion criteria: All newborns with a gestational age of 34 weeks or more delivered in the hospital during the study period were included in the study.

Exclusion criteria: Preterm neonates with gestational age less than 34 weeks, blood transfusion prior to sampling, refusal of informed consent and outborn babies with age more than 5 days were excluded from the study.

Data collection and procedure: Before sampling well written informed consent was taken from either of the parents. 
The blood sample was taken in a sterile container under aseptic precautions, between 3-5 days of life to minimize the false positive high TSH values due to the physiological neonatal surge that elevates TSH level and causes T4, T3 changes in 1-2 days. In cases with a healthy newborn baby, sampling was done between 3-5 days.

Detailed antenatal history, parity, medical history, thyroid status, and community were recorded on a predesigned proforma. Details of the baby were recorded on a separate proforma. TSH was estimated within $24 \mathrm{~h}$ by chemiluminescence Immunoassay (kit supplied by Roche E411). Newborn with TSH value more than $20 \mu$ IU/L were labeled as a case of congenital Hypothyroidism and whose values were between 10-20 $\mu \mathrm{IU} / \mathrm{L}$ were followed up with repeat TSH level after weeks.

Data analysis: All the data were analyzed by descriptive statistics and expressed in terms of percentage and tabulated form. The analysis was done on Microsoft Excel 2013.

Ethical permission: The study was approved by the institutional ethics committee. A well written informed consent was taken from all of the participants after explaining the details, benefits, and risks to them.

Interpretation of screening test: Venous TSH $>20 \mathrm{mIU} / \mathrm{L}$ (serum units) is taken as the cut-off for postnatal screen samples after 48-72 hours of age is to be taken as positive newborn TSH between 10$20 \mathrm{mIU} / \mathrm{L}$ were taken for a second TSH sample at 7 to 10 days of age.

\section{Results}

A total of 1363 babies were enrolled, but 1272 were an eligible candidate for the study period. Those, not eligible candidates received a blood transfusion, death within 3 days, left against medical advice (LAMA) or shifted to other hospitals and nonconsenting of parents for the study. Out of the delivered babies, 820 were born by lower section caesarian section and 452 were vaginally delivered and there were 36 mothers who were hypothyroid and were on medication.

Numbers of term deliveries were 1109 and preterm deliveries were 163, with 665 (52.28\%) males and $607(47.72 \%)$ female babies. Of the total eligible neonates, 1109 were term babies and 163 were preterm babies with more than 34 weeks (Table 1 ).
Neonatal thyroid-stimulating hormone was estimated in all 1272 neonates out of which 2 cases were positive for $\mathrm{CH}, 12$ cases had initially high values between 10-19 $\mathrm{\mu IU} / \mathrm{L}$ which were later on repeat testing after two weeks were found to be in normal limits and rest all 1258 cases were normal (Table 2). From the 2 positive cases of $\mathrm{CH}$, one baby was of Downs's syndrome on 12.5 mcg of Eltroxcin and one baby was positive of elderly primi mother on $25 \mathrm{mcg}$ of medication and on regular follow up since last 5 months.

Table-1: Demographic profile from the study.

\begin{tabular}{|c|c|c|}
\hline Variable & Number & Percentage \\
\hline \multicolumn{3}{|l|}{ Mother's age (Years) } \\
\hline$\geq 18-25$ & 673 & 52.9 \\
\hline $26-30$ & 459 & 36.08 \\
\hline$>30$ & 140 & 11.02 \\
\hline \multicolumn{3}{|l|}{ Sex } \\
\hline Male & 665 & 52.28 \\
\hline Female & 607 & 47.72 \\
\hline \multicolumn{3}{|l|}{ Gestational age (Weeks) } \\
\hline $34-<37$ weeks (Preterm) & 163 & 12.81 \\
\hline$\geq 37$ weeks $($ Term) & 1109 & 87.19 \\
\hline \multicolumn{3}{|l|}{ Birth weight $(\mathrm{Kg})$} \\
\hline$<2.5 \mathrm{~kg}$ & 365 & 28.7 \\
\hline$\geq 2.5 \mathrm{~kg}$ and above & 907 & 71.3 \\
\hline \multicolumn{3}{|l|}{ Mode of delivery } \\
\hline LSCS & 820 & 64.47 \\
\hline Normal & 452 & 35.53 \\
\hline Maternal history of hypothyroidism & 84 & 6.6 \\
\hline
\end{tabular}

Table-2: TSH value among Neonates.

\begin{tabular}{|l|l|l|}
\hline \multicolumn{1}{|c|}{ Variable } & TSH value at 48-72hrs & TSH value after 14days \\
\hline TSH $<10 \mathrm{mIU} / \mathrm{L}$ & 1258 & Normal \\
\hline TSH $10-20 \mathrm{mIU} / \mathrm{L}$ & 12 & Normal \\
\hline TSH $>20 \mathrm{mIU} / \mathrm{L}$ & 02 & Higher \\
\hline
\end{tabular}

\section{Discussion}

Hypothyroidism results from a deficient production of thyroid hormone either from a defect in the gland itself as a result of reduced thyroid-stimulating hormone. The disorder may be congenital or acquired. $\mathrm{CH}$ is commonly due to non-genetic cause, deficient thyroid embryogenesis leading to thyroid gland agenesis or dysgenesis while few cases are due to genetic reason or inborn error of metabolism while impaired thyroxin (T4) synthesis. Many mutations are also implicated in $\mathrm{CH}$, namely that if in transcription factor PAX-8 and TTF- 2 and in genetic coding for sodium iodide symporter, thyroid peroxidase and thyroglobulin are also responsible 
For causing $\mathrm{CH}[6,7]$. Deficiency of maternal iodine is another common contributing factor resulting in $\mathrm{CH}$ consequently leading to abnormal fetal depression. Transfer of excess of iodine to the fetus through placenta or secretion of iodine in breast milk may also result in $\mathrm{CH}$ among neonates $[8,9]$.

As consanguinity is common in our country, $\mathrm{CH}$ although autosomal recessive in inheritance is expressed more commonly than in other developed countries.

Screening for $\mathrm{CH}$ by monitoring thyroid level at birth remains one of the most cost-effective tools in preventing mental retardation in these children. This neonatal screening is the norm in developed countries but unfortunately, such a nationwide program is non- existent in our country. There are two main screening ways for $\mathrm{CH}$ : primary $\mathrm{T} 4$ testing (with backup $\mathrm{TSH}$ ) or primary thyroid-stimulating hormone (TSH) testing. In some states of USA, T4 estimation is done for screening while some US states screen T4 and TSH simultaneously [10], which may not be cost-effective for developing countries like India. The primary TSH screen is more sensitive and specific for the diagnosis of primary $\mathrm{CH}$ compared to the T4 screen [11].

In India, the first Newborn Screening program for $\mathrm{CH}$ was at BJ Wadia Hospital Mumbai in 1982 using cord blood TSH and subsequently in 1984 using postnatal dried blood spot $[12,13]$. A study conducted in 2001 reported that only $5 \%-10 \%$ of children have been diagnosed with $\mathrm{CH}$ under a screening program in India [14]. Therefore, India warrants an effective, robust, and cost-effective screening program. A study conducted by ICMR which screened for inborn metabolic disorders in neonates from the years 2007 to 2012 from Delhi, Mumbai, Chennai, Hyderabad, and Kolkata reported an incidence for $\mathrm{CH}$ of $1: 1130$ newborns. [15]

The most influential drawback of the present study is the small sample size. Large population-based studies are required to gauge and calculate the incidence of $\mathrm{CH}$ in our country. Therefore, India warrants a simple, effective, fast, and cost-effective screening program with adequate infrastructure, space, and resources as a part of Newborn screening.

In India, an attempt has been made to screen neonates for thyroid abnormalities at various centers, but a national program does not exist at present.
The method of screening is also not uniform. Various cut-offs for TSH levels have been used in different studies $[16,17,18]$, but it has been accepted to take cut-off of $>20 \mu \mathrm{IU} / \mathrm{mL}$ for recall.

Due to the subtle manifestation of $\mathrm{CH}$ in the newborn period, it is often missed which results in delayed diagnosis, mental retardation and growth failure hence it is very important to implement a neonatal screening program.

Whilst taking into consideration the mode/type of deliveries the newborns delivered by elective Caesarean Section had significantly lower mean levels of cord blood TSH as compared to those delivered by vaginal delivery or emergency lower segment cesarean section. This difference can be explained on the basis of a surge in catecholamine secretion during the process of parturition and this can be more in asphyxiated newborns and in vaginally delivered newborns compared to those born by elective cesarean section $[19,20]$. In contrast, two studies have shown no difference in neonatal TSH levels according to the mode of delivery $[21,22]$.

Babies who received active intervention in the form of resuscitation and LSCS for fetal distress were expected to have raised TSH levels as a response to the stress that they had endured due to the procedures. Thus raised TSH in these neonates has to be interpreted in that context.

The incidence of consanguinity is very common in India and varies from $1 \%$ in the northern region to $30 \%$ in Karnataka [23]. Thus, the incidence of expression of autosomal recessive $\mathrm{CH}$ is raised in these geographic regions.

In our country implementation of the universal screening program is difficult due to the high number of non-institutional/home deliveries and early discharge of patients. A study conducted among the urban Delhi population in 2014 reported $53 \%$ home births [24]. But now the health statistics of our country have improved due to an increased number of institutional deliveries and the mortality rate has declined but now we have to think beyond this implement newborn screening (NBS) to prevent neuro disability.

Being diverse in all aspects, it is very difficult to launch a universal program of NBS. So, the government should prepare such a program that should be effective, rapid, cost-effective and improve coverage from the grass-root level. 
In the present study, the overall incidence is $1: 636$ while some studies showed 1 in 248 and 1 in 1700 $[25,26]$. This may be due to less sample size and geographic variation. The prevalence of $\mathrm{CH}$ was 1.57 per thousand live birth. The male to female ratio in the present study was $1: 1$ while $1.2: 1$ was in Japan [27] in Bosnia [28] and 1.8:1 in Saudia Arabia [29]. However, some studies did not find any significant differences in mean TSH level according to sex $[30,31]$ Out of the two babies who were diagnosed $\mathrm{CH}$ both were male. The first one had Down's syndrome with cyanotic congenital heart disease (CHD) and second, it was of an elderly primi mother. At present both are under treatment with control.

Studies have reported that TSH levels increase with increasing gestational age however higher TSH levels in preterm than in terms have been reported. There is no statistical significance between low birth weight and normal weight babies with respect to theirs TSH values in the present study, but some studies have reported that low birth weight is related to high TSH [30].

Limitations: Geographic ethnic differences are responsible for this wide variation in incidence and a cohort size of 1272 samples is too less to access incidence. To have more conclusive evidence for the current findings, the studies to be conducted in the future should be designed in order to evaluate more babies/population as well as include other maternal and perinatal parameters in the analysis.

\section{Conclusion}

Timely diagnosis and treatment of $\mathrm{CH}$ are important in order to prevent psychomotor development disability \&improve school progress. NBS is the need of the hour for early diagnosis of $\mathrm{CH}$, which is simple, fast as well as cost-effective. Although universal newborn screening is implemented in developed countries; our country has still not implemented this universally. The policy should be formed so that this can be implemented at the grass-root level from ASHA workers to PHCs level to government/ private medical colleges.

\section{What does the study add to the existing knowledge?}

New-born screening for $\mathrm{CH}$ if made compulsory in all centers has the potential to prevent intellectual impairment in India.
Recommendations: Increase societal awareness of $\mathrm{CH}$ and its identification by newborn screening. Health care providers should inform all pregnant mothers during the antenatal visit about $\mathrm{CH}$, newborn screening and its cost-effective benefit. Newborn screening should be mandatory and ultimately made free by legislation, just the way it is for birth registration and immunization.

\section{Author's contributions}

Dr. Saurabh Kumar, Dr. Minhajuddin Ahmed, and Dr. Nitesh Upadhyay reviewed the literature, drafted the manuscript, obtained extensive inputs from the editorial team, and finalized the manuscript incorporating these inputs.

\section{Acknowledgment}

The authors would like to express our deep gratitude to all parents who consented to volunteer in this project. The authors are grateful to Dr. Manal Ashraf Ali, Associate Professor, Department of Pathology, Chirayu Medical College, for the help rendered.

\section{Reference}

01. Lafranchi S, Hypothyroidism. In- Behrman RE, Kleigman RM, Jenson HB editors, Nelson Textbook of Pediatrics. 17th ed, Philadelphia- Saunders. 2004;1872-1879. [Crossref][PubMed][Google Scholar]

02. La Franchi S. Thyroid, Embryology and Physiology- A Current Review of Pediatrics Endocrinology. Philadelphia, USA- WB Saunders. 1993;173. [Crossref][PubMed][Google Scholar]

03. Vulsma T, Gons MH, de Vijlder JJ. Maternal-fetal transfer of thyroxine in congenital hypothyroidism due to a total organification defect or thyroid agenesis. N Engl J Med. 1989;321(1)13-16. 10.1056/nejm198907063210103 [Crossref] [PubMed][Google Scholar]

04. Szinnai G. Clinical genetics of congenital hypothyroidism. Endocr Dev. 2014;26;60-78. doi: 10.1159/000363156 [Crossref][PubMed][Google Scholar]

05. Rastogi MV, LaFranchi SH. Congenital Hypothyroidism. Orphanet J Rare Dis. 2010;5;17. doi: 10.1186/1750-1172-5-17 [Crossref][PubMed] [Google Scholar] 
06. Vassart G, Dumont JE, Refetoff S. Thyroid disorders, In- Scriver CR, Beaudet AL, Sly WS, Valle $D$, editors- The Metabolic and Molecular Bases of Inherited Disease. New York- McGraw-Hill, Inc. 1995;2917-8. [Crossref][PubMed][Google Scholar]

07. La Franchi S. Congenital hypothyroidismEtiologies, diagnosis, and management. Thyroid. 1999;9(7)735-740. doi: 10.1089/thy.1999.9.735 [Crossref][PubMed][Google Scholar]

08. Connelly KJ, Boston BA, Pearce EN, Sesser D, Snyder D, Braverman LE, et al. Congenital hypothyroidism caused by excess prenatal maternal iodine ingestion. J Pediatr. 2012;161(4)760-762. doi: 10.1016/j.jpeds.2012.05.057 [Crossref] [PubMed][Google Scholar]

09. Otten JJ, Hellwig JP, Meyers LD. Dietary Reference Intakes- The Essential Guide to Nutrient Requirements. Washington, DC- National Academies Press. 2006. [Crossref][PubMed][Google Scholar]

10. LaFranchi SH. Newborn screening strategies for congenital hypothyroidism- an update. J Inherit Metab Dis. 2010;33(2)S225-S233. doi: 10.1007/s10545-010-9062-1 [Crossref][PubMed] [Google Scholar]

11. Walfish PG. Evaluation of three thyroid-function screening tests for detecting congenital hypothyroidism. Lancet. 1976;1(7971)1208-1210. doi: 10.1016/s0140-6736(76)92159-0 [Crossref] [PubMed][Google Scholar]

12. Colaco MP, Desai MP, Ajgaonkar AR, et al. Neonatal screening for hypothyroidism. Indian Pediatr. 1984;21;695-700. [Crossref][PubMed] [Google Scholar]

13. Desai MP, Upadhye $P$, Colaco MP, Mehre $M$, Naik SP, Vaz FE, Nair N, Thomas M. Neonatal screening for congenital hypothyroidism using the filter paper thyroxine technique. Indian $]$ Med Res. 1994;100;36-42. [Crossref][PubMed][Google Scholar]

14. Mesai MP, Desai MP, Bhatia V, Menon PS. The thyroid gland, In- Pediatric Endocrine Disorders. 1st ed, New Delhi- Orient Longman. 2001;183-202. [Crossref][PubMed][Google Scholar]

15. Verma IC, Bijarnia, Mahay S, Jhingan G, Verma J. Newborn screening- Need of the hour in India. Indian J Pediatr. 2015;82(1)61-70. doi: 10.1007/s12098-014-1615-0 [Crossref][PubMed] [Google Scholar]
16. Desai MP, Colaco MP, Ajgaonkar AR, Mahadik CV, Vas FE, Rege VV, et al. Neonatal screening for congenital hypothyroidism in a developing countryproblems and strategies. Indian J Pediatr. 1987;54;571-581. doi: 10.1007/BF02749056 [Crossref][PubMed][Google Scholar]

17. Ogunkeye OO, Roluga AI, Khan FA. Resetting the detection level of cord blood thyroid stimulating hormone (TSH) for the diagnosis of congenital hypothyroidism. J Trop Pediatr. 2008;54(1)74-77. doi: 10.1093/tropej/fmm082 [Crossref][PubMed] [Google Scholar]

18. G Kaur, J Srivastav, S Jain, D Chawla, BS Chavan, R Atwal, et al. Preliminary report on neonatal screening for congenital hypothyroidism, congenital adrenal hyperplasia and glucose-6phosphate dehydrogenase deficiency- A Chandigarh experience. Indian J Pediatr. 2010;77(9)969-973. doi: $\quad 10.1007 / s 12098-010-0150-x \quad$ [Crossref] [PubMed][Google Scholar]

19. Rico AJ, Prieto-Lloret J, Gonzalez C, Rigual R. Hypoxia and acidosis increase the secretion of catecholamines in the neonatal rat adrenal medullaan in vitro study. Am J Physiol Cell Physiol. 2005; 289(6)C1417-C25. doi: 10.1152/ajpcell.00023.2005 [Crossref][PubMed][Google Scholar]

20. Gülmezoglu AM, Mahomed K, Hofmeyr GJ, NikodemVC, Kramer T. Fetal and maternal catecholamine levels at delivery. J Perinat Med. $1996 ; 24(6) 687-691$.

doi: 10.1515/jpme.1996.24.6.687 [Crossref][PubMed] [Google Scholar]

21. Herbstman J, Apelberg BJ, Witter FR, Panny S, Goldman LR. Maternal, infant, and delivery factors associated with neonatal thyroid hormone status. Thyroid. 2008;18;67-76. doi: 10.1089/thy.2007.0180 [Crossref][PubMed][Google Scholar]

22. Trumpff $\mathrm{C}$, Vandevijvere $\mathrm{S}$, Moreno-Reyes $\mathrm{R}$, Vanderpas J, Tafforeau J, Van Oyen $H$, et al. Neonatal thyroid-stimulating hormone level is influenced by neonatal, maternal, and pregnancy factors. Nutr Res. 2015;35;975-981. doi: 10.1016/j.nutres.2015.09.002 [Crossref][PubMed] [Google Scholar]

23. Devi $A R$, Rao $A N$, Bittles $A H$. Inbreeding and the incidence of childhood genetic disorders in Karnataka, South India. J Med Genet. 1987;24(6)362-365. doi: 10.1136\%2Fjmg.24.6.362 [Crossref][PubMed][Google Scholar] 
24. Devasenapathy N, George MS, Ghosh Jerath S, Singh A, Negandhi $H$, Alagh $G$, et al. Why women choose to give birth at home- A situational analysis from urban slums of Delhi. BMJ Open. 2014;4;e004401. doi: 10.1136/bmjopen-2013004401 [Crossref][PubMed][Google Scholar]

25. Khadilkar V, Khadilkar A, Cowasji H. Neonatal thyroid screening program using filter paper method. Cape News. 2002;6;1. [Crossref][PubMed] [Google Scholar]

26. Rama Devi AR, Naushad SM. Newborn screening in India. Indian J Pediatr. 2004;71(2)157-60. doi: 10.1007/bf02723099 [Crossref][PubMed][Google Scholar]

27. Miyai $\mathrm{K}$, Inaoka $\mathrm{K}$, Miyagi $\mathrm{T}$. Committee for Newborn and Infant Screening in Osaka (CONISO) Further studies on episodic occurrence of congenital dysgenetic hypothyroidism in Osaka, Japan. End J. 2005;52(5)599-603. doi: 10.1507/endocrj.52.599 [Crossref][PubMed][Google Scholar]
28. Tahirovic $\mathrm{H}$, Toromanovic A. Neonatal screening for congenital hypothyroidism in the Federation of Bosnia and Herzegovina- eight years' experience. Eur J Pediatr. 2009;168(5)629-631. doi: 10.1007/s00431-008-0801-3 [Crossref][PubMed] [Google Scholar]

29. Henry G, Sobki SH, Othman JM. Screening for congenital hypothyroidism. Saudi Med J. 2002;23(5)529-535. [Crossref][PubMed][Google Scholar]

30. Lain SJ, Roberts CL, Wilcken B, Wiley V, Jack MM, Nassar N. Using record linkage to investigate perinatal factors and neonatal thyroid-stimulating hormone. J Paediatr Child Health. 2015;51(6)620625. doi: 10.1111/jpc.12783 [Crossref][PubMed] [Google Scholar]

31. Raj S, Baburaj S, George J, Abraham B, Singh S. Cord blood TSH level variations in newbornExperience from a rural centre in Southern India. J Clinic Diagnos Res- JCDR. 2014;8(7)PC18. doi: 10.7860\%2FJCDR\%2F2014\%2F9058.4603 [Crossref][PubMed][Google Scholar] 